\title{
Programas de treinamento em criatividade: conhecendo as práticas e resultados
}

\author{
Tatiana de Cássia Nakano
}

\begin{abstract}
Resumo
Considerando-se a criatividade enquanto potencial a ser desenvolvido em todos os indivíduos e, portanto, uma característica passível de ser incentivada e treinada, cujos benefícios têm sido destacados principalmente no ambiente escolar, este trabalho teve como finalidade verificar a forma como os programas de treinamento em criatividade vêm sendo implementados e os resultados que vêm sendo obtidos, visando traçar um quadro dos ganhos resultantes desse tipo de programa. Uma seleção de pesquisas encontradas na literatura foi feita, apresentadas de acordo com o nível educacional dos participantes envolvidos, cujos resultados permitiram verificar que a maior parte dos programas aponta resultados positivos e ganhos provenientes desse treinamento, quando se comparam grupos experimentais e controle, sendo, a maior parte deles, desenvolvidos junto a estudantes do ensino fundamental. A análise das pesquisas aponta para diferentes possibilidades de incentivo e treino da criatividade a partir de técnicas diferenciadas, instrumental e planejamento diversificado.
\end{abstract}

Palavras-chave: Criatividade, desenvolvimento da criatividade, estimulação criativa.

\section{Creativity's training programs: learning the practices and the results}

\begin{abstract}
In this paper we aim at presenting the results of research on creativity training programs. We argue that creativity is a potential to be developed in all individuals and we consider that creativity can be trained and encouraged, bringing benefits to the school environment, We aim at identifying how the programs are being implemented and what are the results obtained from these programs. A selection of studies of the literature was presented according to the educational level of participants involved. Our findings reveal that most of the programs shows positive results when comparing experimental and control groups, and, most of them developed with students of elementary school. Our analysis points to different incentives and training opportunities for creativity, from various techniques and diverse planning and instruments.
\end{abstract}

Key-words: Creativity, development of creativity, creative stimulation.

\section{Programas de entrenamiento en creatividad: conociendo las prácticas y resultados}

\section{Resumen}

La creatividad es comprendida como potencial a ser desarrollado en todos los individuos y, por lo tanto, una característica pasible de ser incentivada y entrenada. Considerando que sus beneficios han sido destacados, principalmente, en ambiente escolar este trabajo tuvo como finalidad verificar la forma cómo los programas de entrenamiento en creatividad son implementados y los resultados que han sido obtenidos, buscando delinear un cuadro de las ganancias resultantes de ese tipo de programa. Se hizo una selección de investigaciones encontradas en la literatura, presentadas de acuerdo con el nivel educacional de los participantes. Los resultados permitieron verificar que la mayor parte de los programas señala aspectos positivos e ganancias provenientes de ese entrenamiento cuando se comparan grupos experimentales y de control, siendo la mayor parte de ellos desarrollados con estudiantes de enseñanza básica. El análisis de las investigaciones señala diferentes posibilidades de incentivo y entrenamiento de la creatividad a partir de técnicas diferenciadas, instrumental y planificación diversificada.

Palabras Clave: Creatividad, desarrollo de la creatividad, estimulación creativa. 


\section{Introdução}

Atualmente, a criatividade tem sido uma característica cada vez mais valorizada em vários contextos (escolar, organizacional e social), de maneira que o pensamento criativo tem sido frequentemente considerado como um diferencial de pessoas que apresentam capacidade intelectual superior (Lins \& Miyata, 2008). Diante dessa constatação, um questionamento se tem feito presente no meio científico: é possível desenvolver a criatividade? Como? Buscando responder a essa questão, pesquisadores de diversos países têm criado e aplicado programas de treinamento criativo, visualizados como um conjunto de métodos, técnicas, exercícios e estratégias, cujo objetivo seria desenvolver as aptidões, por meio da estimulação de atitudes criativas, realizados em grupos ou individualmente (De la Torre, 2008). Tais programas baseiam-se na crença de que a criatividade representa um conjunto de aptidões que podem ser aprendidas ou desenvolvidas, por meio do ensino e da prática, principalmente através de programas e estratégias orientadas a favorecer o pensamento criativo, os quais têm gerado grande repercussão (Sánchez, Martínez, García, Renzulli, \& Costa, 2002).

Muitos pesquisadores acreditam que a criatividade está presente em todas as pessoas, ao menos enquanto potencial, podendo emergir espontaneamente desde que não seja inibida ou bloqueada (Cropley, 1999). Novaes (1972) afirma que, sem dúvida, a criatividade pode ser desenvolvida, desde que se reforcem as funções envolvidas e se consiga uma melhor utilização dos recursos individuais, "tendo grande influência o processo educativo e as influências sociais, estando esse desenvolvimento condicionado aos limites individuais" (p.80). Nesse sentido, diversas pesquisas e estudos sobre o desenvolvimento da criatividade têm sido realizados, dado o fato de que as pesquisas na área de programas de desenvolvimento da criatividade têm, segundo Alencar (2001), demonstrado as mudanças que são possíveis de ocorrer, principalmente aquelas relacionadas ao comportamento de professores, alunos e profissionais de outras áreas após participação em programa de criatividade. Tais programas trazem como objetivos não só o despertar das habilidades e do potencial criativo, mas também a apresentação de recursos para aproveitamento do mesmo, incluindo técnicas de resolução criativa de problemas e tomada de consciência sobre os fatores inibidores da criatividade.

De acordo com Alencar (1996), "diversas são as técnicas de resolução criativa de problemas já desenvolvidas com o objetivo de facilitar ao indivíduo o alcance de soluções únicas e originais" (p.75), cujo domínio vem sendo um dos principais focos dos programas de treinamento da criatividade. De acordo com Cropley (1999), o treinamento formal tem se mostrado mais efetivo do que a simples redução do nível de formalidade em sala de aula ou a exposição da criança a uma variedade de experiências. Assim, duas questões se têm feito presentes: como o treinamento e utilização dessas técnicas podem influenciar a criatividade individual? A aplicação dessas técnicas atua no sentido de promover e desenvolver outras formas de criatividade?
Embora internacionalmente difundidos, estudos publicados sobre o impacto dos programas de enriquecimento ainda são em pequeno número na literatura nacional. "Apesar do reconhecimento da importância de se estimular as habilidades criativas, pouco se tem feito para favorecer seu desenvolvimento e manifestação" (Alencar \& Fleith, 2003, p.183). Além de se verificar uma grande divergência entre os tipos de programas existentes, também os planos de investigação variam muito em termos das amostras e das metodologias empregadas, de forma que estas dificuldades parecem dever-se, em parte, de acordo com Oliveira (2007), à complexidade em selecionar a metodologia de avaliação mais adequada. Opinião similar é apresentada por Cropley (1999), ao destacar que os resultados do treinamento criativo que têm sido apontados não têm se mostrado simples e diretos, sendo, muitas vezes, bastante diferentes. Isso resulta do fato de que estes resultados acabam por serem influenciados pela metodologia da pesquisa, assim como as condições em que os dados de critérios são obtidos.

Diante das diversidades de propostas que vêm sendo testadas, o que se tem visto é que o planejamento desses programas, elaborados para estimular a criatividade, tem seu foco alterado em função do conteúdo, do modelo de criatividade escolhido e da experiência acumulada na avaliação destes programas (Fernández \& López, 1998). Dentre as técnicas e procedimentos de enriquecimento mais utilizados, Cropley (1999) destaca a realização de sessões criativas voltadas à capacitação de professores, conduzidas por um especialista, visitas a diferentes locais artísticos, atividades em finais de semana e acampamentos de férias voltados à estimulação criativa, brainstorming, workshops de criatividade, incentivo ao uso de materiais não usuais, assim como o incremento de técnicas de resolução de problemas.

No Brasil, vários estudos foram realizados a fim de investigar o efeito de diferentes procedimentos e programas na criatividade do aluno. O interesse pelo tema teve início, segundo Alencar e Fleith (2003), na década de 1970, atingindo seu pico no período de 1985 a 1995. Ainda de acordo com as autoras, programas foram conduzidos com alunos e professores de diferentes níveis educacionais, tendo, a maior parte das pesquisas, investigado os efeitos dos programas de treinamento da criatividade em relação a variáveis cognitivas, tais como rendimento acadêmico e habilidades do pensamento criativo e afetivas (como o autoconceito) em alunos do Ensino Fundamental. Nesse mesmo sentido, Fadel e Wechsler (2011) apontam que a maioria dos estudos realizados até o momento sobre programas de desenvolvimento de criatividade tiveram como amostra estudantes e professores de ensino fundamental e médio.

Faz-se assim notar uma grande lacuna, visto que, historicamente, segundo apontamento de Pereira e Guimarães (2007), o grande desafio da educação tem sido reconhecer a diversidade de alunos que se encontram nos sistemas de ensino, em termos de ritmos, estilos, interesses e potencialidades, a fim de permitir que um maior número possa beneficiar-se de contextos educacionais que favoreçam um desenvolvimento pleno. Infelizmente, pouca ou quase ne- 
nhuma produção é encontrada nos demais níveis educacionais e junto a professores, ou ainda visando ao treinamento criativo em outros contextos, tal como o organizacional.

Dessa maneira, o que se pode notar é a veiculação da ideia da criatividade enquanto potencial treinável (De la Torre, 2008), embora, como já salientado, sem comprovações acerca da sua eficácia. Autores, tais como Morais e Azevedo (2008), apontam que, na avaliação da eficácia desses programas, parece haver apenas uma evidência limitada de que se conseguem indivíduos mais criativos com o treino, já que "há poucos estudos robustos a nível de controle de efeitos, havendo muita especulação nessa área, sendo questionáveis a transferência do treino e a sua duração" (p.163). Entretanto, essas mesmas autoras, diante da desconfiança acerca dos resultados que podem ser obtidos, ressaltam um importante questionamento: Qual seria o maior erro? Tentar a promoção da criatividade, não sendo esta eventualmente rentável ou não investir no treino havendo a possibilidade da mudança? O segundo caso parece ser, segundo elas, inequivocadamente o pior. Nesse sentido, Bahia (2008) chama a atenção para o fato de que, se assumirmos que todas as pessoas são potencialmente criativas, uma das condições fundamentais dos programas de desenvolvimento da criatividade estará atendida, de forma a justificar o seu desenvolvimento.

Dada a importância dos programas de estimulação e treinamento da criatividade, ressaltada por vários pesquisadores, a presente pesquisa, de caráter bibliográfico, teve como objetivo o desafio de mapear e avaliar o conhecimento, os métodos e técnicas que vêm sendo empregados na temática, na tentativa de identificar o que vem sendo destacado nas produções científicas e acadêmicas. Pesquisas de revisão bibliográfica visam responder, de acordo com Ferreira (2002), "que aspectos e dimensões vêm sendo destacados e privilegiados em diferentes épocas e lugares, de que formas e em que condições têm sido produzidas certas dissertações de mestrado, teses de doutorado e publicações em periódicos" (p.258).

Dada a tendência atual, em países os mais diversos, "da necessidade de se promover oportunidades especiais para alunos com maior potencial” (Alencar, 2001, p.157), ressalta-se a importância de se estimular os talentos enquanto os mesmos ainda são potenciais, assim como oferecer condições que irão facilitar o seu desenvolvimento e expressão se faz necessário. Por esses motivos, o conhecimento dos resultados e das práticas dos programas que vêm sendo desenvolvidos adquire uma importância científica no sentido de que trabalhos sobre produção científica fornecem um mapeamento das contribuições, necessidades e déficits da produção em determinada área (Lustoza, Oliveira, \& Mello, 2010), dada ainda a possibilidade de assim se levantar possíveis diretrizes para novos temas de pesquisa (Witter, 2005). Socialmente, o conhecimento das práticas pode ser usado de forma positiva pelos pesquisadores, evitando-se que muitos talentos sejam desperdiçados em nosso país, dada a importâncial da identificação precoce das possibilidades criadoras. Partindo-se do princípio de que a variação do potencial criador dependerá das oportunidades que os indivíduos terão em expressá-lo, os programas de treinamento podem ser visualizados como um incremento dessas oportunidades.

Buscando-se respostas acerca dos ganhos provenientes desse tipo de programa e diante da diversidade de estratégias que vêm sendo realizadas, este trabalho teve como objetivo revisar a produção científica sobre programas de treinamento da criatividade com o objetivo de conhecer as práticas e resultados obtidos.

\section{Método}

Como estratégia de levantamento de material, três importantes bases de dados de publicações periódicas, sendo duas nacionais (Scientific Electronic Library Online SciELO e Periódicos Eletrônicos em Psicologia - PEPSIC) e uma internacional (American Psychological Association PsycNet), além de uma base de dados de teses e dissertações (Capes), foram consultadas.

A seleção das bases de dados deu-se de acordo com as recomendações de Berwanger, Suzumura, Buehler e Oliveira (2007), os quais destacam que uma revisão sistemática adequadamente delineada não deve restringir-se ao uso de apenas um único banco de dados, dado o fato de que o mesmo pode não conter todos os artigos publicados sobre o tema (principalmente se considerarmos a alta exigência para indexação das revistas na primeira base citada - Scielo). Dessa forma, torna-se fundamental, segundo os autores, a consulta a outras bases (o que foi feito ao fazer uso de outras duas bases, uma nacional e outra internacional), assim como a verificação das referências citadas nos artigos encontrados. Os autores ainda reforçam a importância da tentativa de se identificar estudos não publicados nas bases de dados de teses e dissertações das principais universidades contidas nas bases digitais, o que foi feito a partir do uso do banco da Capes. Dessa forma, bases bastante completas para acesso à produção científica nacional e internacional foram consultadas.

A partir do termo "criatividade", tido como descritor, sem delimitação de ano de publicação, todos os resumos identificados nas bases foram visualizados, sendo posteriormente selecionados aqueles que envolviam programas de treinamento, estimulação e desenvolvimento da criatividade, os quais foram consultados na íntegra (no caso dos artigos e trabalhos acadêmicos disponíveis, sendo, nos demais casos, consultado somente o resumo do trabalho). Uma segunda estratégia consistiu na tentativa de localização de trabalhos que eram citados nos trabalhos localizados, por meio da consulta às referências bibliográficas, devendo-se salientar, entretanto, que, por meio dessa estratégia, somente alguns trabalhos conseguiram ser localizados, embora, muitas vezes, outros trabalhos também envolvessem a temática sem que, no entanto, o acesso aos mesmos fosse possível, sendo essa uma limitação a ser apontada no estudo atual. Some-se a isso o fato de que as bases de dados, principalmente periódicas, tornaram-se eletrônicas há um 
período de tempo relativamente recente, de forma que tal fato pode ter atuado como limitador, de maneira que alguns trabalhos existentes (com data de publicação mais antiga) provavelmente não foram localizados. Assim, um resumo de cada estudo é apresentado com o objetivo de verificar os métodos utilizados, os resultados obtidos, os participantes envolvidos e as diferenças entre eles. Considerando-se que todos os estudos encontrados foram, sem exceção, desenvolvidos em ambientes educacionais, optou-se pelo agrupamento dos mesmos de acordo com o nível educacional, a fim de facilitar sua apresentação.

Uma ressalva fica por conta de que, ao se falar sobre programas de treinamento criativo, torna-se importante destacar que, muitas vezes, tais programas acabam sendo inseridos e desenvolvidos dentro de programas mais amplos, voltados ao atendimento dos superdotados. Tal fato decorre do reconhecimento da convergência de múltiplas dimensões, tais como inteligência, criatividade, liderança, motivação, habilidades artísticas e interpessoais, além dos contextos sociais (Feldman, 2000; Gagné, 2005; Kaufman \& Sternberg, 2008) como componentes da superdotação dentro das teorias mais atuais. Assim, os programas apresentados envolvem não somente programas de estimulação da criatividade, mas também programas voltados à superdotação, nos quais essa característica também é contemplada, tendo-se focado, nesses casos, somente os resultados obtidos em relação ao potencial criativo dos participantes.

Como forma de apresentação dos dados, optou-se não pelo fornecimento de estatística descritiva relacionadas às produções (por exemplo, análise da frequência e porcentagem referente a categorias tais como ano de publicação, amostra e instrumentos utilizados), mas pelo fornecimento dessas informações de forma mais detalhada em cada um dos estudos, de forma a se constituir em um estudo mais qualitativo do que quantitativo. Assim, resumos de cada pesquisa são apresentados, estando os mesmos agrupados por nível de escolaridade dos participantes.

Iniciando-se nas séries pré-escolares, somente dois estudos foram encontrados neste nível educacional. No primeiro, Bertonha (1995) buscou testar o efeito de um programa para desenvolvimento da criatividade em 26 crianças da pré-escola. Dois grupos de crianças, controle e experimental, responderam ao Teste Pensando Criativamente com Figuras de Torrance, realizando também desenhos livres em sessões individuais. Paralelamente, dois grupos de professores foram formados: um experimental (o qual participou de um programa para desenvolvimento das características da pessoa criativa, com duração de 6 sessões que tiveram como objetivo o planejamento de aulas criativas, posteriormente ministradas com o auxílio da pesquisadora) e um grupo controle, que não foi envolvido em nenhuma atividade. Os resultados obtidos apontaram que os alunos dos professores que participaram do treinamento apresentaram ganhos nas características de títulos expressivos e movimento, cujos desenhos apresentavam maior presença dessas características do que os desenhos das crianças participantes do grupo controle.
O segundo estudo, desenvolvido por Sánchez e cols. (2002), foi aplicado em 232 alunos, entre cinco e seis anos. O programa, adaptado do Programa para desenvolvimento da criatividade de Renzulli e colaboradores, consta de cinco manuais destinados a favorecer o pensamento divergente de crianças de educação infantil e primária, contendo, cada um, 24 atividades de diferentes níveis de complexidade e abstração. O teste figural de Torrance foi utilizado como medida de avaliação, tendo sido aplicado antes e depois do programa de treinamento em dois grupos, um controle e outro experimental. Os resultados indicaram que as características de flexibilidade e originalidade se mostraram mais sensíveis ao programa, ao passo que fluência e elaboração foram mais resistentes à mudança.

No ensino fundamental, encontra-se a maior parte dos programas desenvolvidos, tanto nacionais quanto internacionais. Nesse nível educacional, Bampi (1995) executou um programa de treinamento com o objetivo de enriquecer a escrita de 31 crianças, com idades entre 9 e 15 anos, de forma a torná-la mais criativa. Um programa de treinamento criativo composto por 11 sessões foi oferecido ao grupo experimental, durante as aulas da disciplina de Português, baseando-se no "Modelo de Incubação para o ensino", de Torrance e Safter. O instrumento utilizado para o pré e pós-teste foi o Teste de Criatividade Verbal de Torrance e redações livres. Os resultados apontaram ganhos significativos em Flexibilidade, além de ganho em outras características criativas cujas diferenças, embora notadas, não se mostraram significativas. Por outro lado, o grupo controle apresentou uma queda geral nos indicadores criativos, de forma que a autora concluiu acerca da importância de programas que visem ao estímulo à criatividade na escrita a fim de prevenir quedas de interesse e produtividade nessa área.

Outro estudo foi desenvolvido por Bighetti (1995), buscando avaliar o efeito da maneira de se contar histórias para crianças sobre sua criatividade. Nesse estudo, 52 crianças, de ambos os sexos, com idades entre 8 e 13 anos, foram divididas em dois grupos, controle e experimental. As crianças do grupo experimental participaram de 8 sessões nas quais foram contadas histórias clássicas e psicopedagógicas utilizando-se a "Técnica criativa de contar histórias", elaborada por Torrance. O grupo controle ouviu as mesmas histórias contadas de forma assistemática. As medidas de pré e pós-teste para o grupo experimental e controle incluíram duas atividades do Teste Pensando Criativamente com Palavras de Torrance, redações livres e perguntas abertas. A análise quantitativa das produções das crianças demonstrou ganhos no grupo experimental nos indicadores de Fluência, Flexibilidade, Elaboração e Expressão de Emoção, assim como um grande interesse pelos temas das histórias, evidenciado nos relatos das crianças.

Pesquisa similar foi desenvolvida por Maimoni (1992) com o objetivo de verificar como o modo de contar histórias tem efeito sobre o comportamento verbal de alunos em fase de escolarização. Quatro modalidades diferentes de treino foram testadas em 20 sessões. Os resultados demonstraram que os alunos com desempenho inicial abaixo da média 
do grupo foram os que mais se beneficiaram do programa, independente da modalidade de treino a que foram submetidos. Os melhores resultados foram obtidos pelo grupo que recebeu a maior quantidade de estimulação visual, auditiva e de reforço, fornecidas através da audição da história, ilustrações em cada trecho e reforço verbal e social oferecido de forma oral pela pesquisadora após a leitura.

Outra pesquisa, desenvolvida por Wechsler (1987), teve como objetivo investigar os efeitos de um programa para estimulação da criatividade em 289 crianças com idades entre 9 e 15 anos, que cursavam a terceira e quarta série do Ensino Fundamental. Para isso, utilizou uma série de avaliações que incluíram testes de inteligência (Figura Humana e Raven), testes de criatividade (Teste de Torrance) e avaliação dos professores, cujos resultados foram utilizados como recurso para a definição de um grupo experimental, composto por 72 crianças que obtiveram os melhores resultados nos testes. Aos dois grupos (experimental e controle), foi oferecido um programa de treinamento criativo, realizado em 23 sessões, com duração de duas horas cada, composta por três a quatro atividades diferentes que visavam habilidades relacionadas com o pensamento criativo. Após o final do programa, os resultados demonstraram ganhos principalmente na área da criatividade figural, motivação, participação, além de rendimento acadêmico. Interessantemente, os maiores ganhos foram obtidos por crianças regulares e não por aquelas que inicialmente apresentaram melhor desempenho. Alencar (1998) relata um trabalho desenvolvido em 1974 junto a 791 alunos, pertencentes a 24 salas de aula de $4^{\text {a }}$ e $5^{\text {a }}$ séries, das quais 16 salas participaram de um programa de criatividade, aplicado pelo professor uma vez por semana durante um semestre. Os demais participantes apenas responderam a testes de pensamento criativo, antes e após o término do programa, constituindo-se em grupo controle. Os resultados evidenciaram a efetividade do programa, visto que os alunos do grupo experimental apresentaram resultados significativamente superiores ao do grupo controle em várias medidas do pensamento criativo, devendo-se destacar ainda o entusiasmo dos participantes, assim como o interesse pelo conteúdo trabalhado no programa.

Outra pesquisa, com o objetivo de avaliar a influência da criatividade sobre o desempenho dos sujeitos em leitura e escrita, foi realizada por Joly (1999) com 80 alunos de $1^{\text {a }}$ a $4^{\text {a }}$ série do Ensino Fundamental, divididos em grupo experimental e controle. O treinamento foi realizado através do oferecimento de programas de leitura, escrita e criatividade, sendo que, para cada programa, foi estabelecida uma avaliação inicial, intermediária e final, fazendo uso da Técnica de Cloze, utilizada de modo convencional ou através de computador. Os resultados demonstraram que o desempenho dos sujeitos do grupo experimental foi qualitativamente superior ao do grupo controle, embora estas diferenças não tenham sido significativas, o que, na opinião da autora, ocorreu devido ao fato de todos os grupos terem apresentado progressos significativos em todos os programas.

Diferentes tipos de estimulação também foram testadas por Alencar (1975), que realizou pesquisa com 578 alunos de $4^{\mathrm{a}}$ e $5^{\mathrm{a}}$ série, divididos em três diferentes programas: programa com reforço do desempenho nos exercícios de criatividade, programa sem reforço do desempenho nos exercícios de criatividade e grupo controle. Como metodologia, utilizou o programa de criatividade de Purdue, que consiste em 28 estórias a respeito de famosos descobridores e inventores, acompanhadas de três a quatro exercícios cujo objetivo seria estimular a originalidade, flexibilidade, fluência e elaboração. O programa foi aplicado uma vez por semana durante 14 semanas consecutivas. Os testes de Torrance foram usados no pré e pós-teste (sendo quatro atividades verbais e quatro figurativas). Os resultados demonstraram que o programa foi efetivo em aumentar as habilidades de pensamento criativo dos sujeitos, entretanto, diferentemente do esperado, o programa que incluía o reforçamento dos alunos nos exercícios de criatividade não resultou em maior aproveitamento, tanto que, para quatro das 12 medidas avaliadas, o programa sem reforço foi mais efetivo do que o programa com reforço. Esse resultado foi interpretado pela pesquisadora como uma hipótese de que os reforçadores podem ter evocado, nos alunos, sentimentos de medo e ansiedade de ser avaliado.

Internacionalmente, três pesquisas desenvolvidas nos Estados Unidos e três em Portugal foram encontradas. Huber, Treffinger e Tracy (1979) visou investigar o efeito do programa Purdue de treinamento da criatividade em 648 estudantes de ensino fundamental nos Estados Unidos, sendo 309 participantes provenientes de sala de atendimento a superdotados e 339 de salas regulares. Metade de cada grupo compôs o grupo experimental e a outra metade, o controle. O programa consiste em 28 histórias e apresentações, que são acompanhadas de exercícios que visam ao desenvolvimento de habilidades verbais e figurativas da criatividade, tendo sido oferecido durante 12 semanas ao grupo experimental. Pré e pós-testes com a bateria de Torrance foram administrados e indicaram melhor desempenho dos estudantes do grupo experimental na medida de fluência verbal.

Cartdelge e Krauser (1963) conduziram um experimento designado para estimular a criatividade de 120 crianças de $1^{\text {a }}$ série do ensino fundamental que foram selecionadas devido ao baixo desempenho em testes de criatividade, dentro de uma amostra inicial de 187 participantes. Dois grupos foram formados, experimental e controle, com 60 participantes cada, sendo que posteriormente cada grupo foi subdividido e a metade dos participantes foi treinado em relação à motivação quantitativa (valorizando a quantidade de ideias dada pelo participante) e, a outra metade, à motivação qualitativa (valorizando apenas as ideias que apresentassem qualidade), em cinco sessões de vinte minutos cada. Os resultados demonstraram que o tipo de treinamento influenciou de forma significativa nas medidas de fluência, flexibilidade e originalidade, a favor do grupo que recebeu treinamento em motivação qualitativa.

Nesse mesmo sentido, Cropley e Feuring (1971), visando investigar o efeito do treinamento da criatividade em 69 alunos de $1^{\text {a }}$ série do Ensino Fundamental, divididas em quatro grupos. $\mathrm{O}$ grupo $\mathrm{A}$ recebeu treinamento no qual eram 
incentivados a fornecer o maior número de ideias, o grupo $\mathrm{B}$ também recebeu treinamento, mas foi incentivado a fornecer respostas interessantes e originais, o grupo $\mathrm{C}$ foi instruído a dar um grande número de ideias, embora não tenha recebido treinamento e, por fim, o grupo $D$ foi instruído a dar ideias interessantes e originais, também sem ter recebido treinamento. A avaliação pré e pós-teste foi realizada fazendo uso do instrumento Forms of the Product Improvement Test, sendo que os resultados indicaram a influência do tipo de treinamento nos escores de flexibilidade e originalidade.

Em Portugal, Miranda e Almeida (2008) apresentam os resultados de um programa de enriquecimento escolar intitulado Odisseia, cujo objetivo seria promover experiências diversificadas para alunos do $5^{\circ}$ e $6^{\circ}$ ano de escolaridade a fim de que os mesmos possam desenvolver e manifestar seus talentos. Os autores salientam que o programa é dividido em três fases, sendo a primeira integrada ao currículo escolar dos alunos, oferecida durante o período de 1 ano letivo em 37 sessões de 90 minutos. Já a segunda fase é desenvolvida em horários extracurriculares, destinando-se a alunos que se destacaram na primeira fase (cerca de $25 \%$ dos alunos que pontuaram no percentil 75 em provas de criatividade e aptidão, sendo necessário ainda elevado nível de aprendizagem e realização acadêmica) e tendo duração de um semestre em 15 sessões que visam estimular os processos de fluência, flexibilidade, elaboração e originalidade, além de resolução criativa de problemas. Por fim, a inclusão na terceira fase baseia-se em alguns critérios tais como bom aproveitamento na segunda fase, QI acima de 120 , nível elevado de criatividade e motivação, além de indicação dos professores. Foi realizada ao longo de um trimestre, em sessões que focaram problemas ou assuntos complexos que a sociedade enfrenta. Como forma de testar a eficácia do programa, sujeitos de um grupo controle e experimental foram submetidos, em três momentos distintos, aos testes de pensamento figural e verbal de Torrance, cujas análises apontaram para ganhos no grupo experimental em raciocínio abstracto, fluência e elaboração verbal, fluência, elaboração e originalidade figurativa, embora, apesar das diferenças não serem significativas, indicaram melhoras no rendimento escolar face aos alunos do grupo controle.

Também em Portugal, Bahia e Trindade (2010) conduziram um estudo junto a 100 alunos do $7^{\circ}$ ano de escolaridade com idade média de 13 anos. As estratégias utilizadas constituíram-se em dois exercícios: (1) combinação de nove figuras geométricas básicas (círculos, quadrados e triângulos) com consequente atribuição de um significado a cada conjunto de combinações formado e seu registro por escrito (realizado em duas aulas de 90 minutos) e (2) leitura de três direitos da criança e sua ilustração, novamente fazendo uso das figuras geométricas (realizado em três aulas de 90 minutos), em um total de cinco aulas dedicadas ao treino. A avaliação da eficácia da implementação de estratégia de promoção da linguagem visual consistiu na análise comparativa dos resultados do exercício pré e outro pós-treinamento, avaliados a partir de seis indicadores: fluência, flexibilidade, originalidade, elaboração, expressividade e apreciação glo- bal. Diferenças significativas foram encontradas em todos os critérios revelando que os alunos interiorizaram e aplicaram um novo veículo de compreensão e expressão de ideias.

Ainda desenvolvido com estudantes do Ensino Fundamental, o Programa de Enriquecimento MAIS (Motivação, Aptidão, Inovação e Socialização), enfatizando, genericamente, a resolução criativa de problemas e a promoção da autorregulação, foi implementado por Antunes (2008) junto a 69 alunos do $5^{\circ}$ e o $6^{\circ}$ ano do Ensino Básico de Portugal, divididos em grupo experimental (alunos que apresentaram meIhor desempenho em critérios cognitivos, criativos, acadêmicos e nomeação pelos professores em um total de 30 alunos) e controle $(n=39)$. A avaliação do programa envolveu uma medida pré e pós-teste nos domínios da cognição/inteligência, da criatividade, do rendimento escolar e do autoconceito para os dois grupos, além de uma avaliação mais qualitativa, que considerou os produtos criativos dos alunos (histórias). Os resultados quantitativos não permitiram, segundo a autora, afirmar a eficácia do programa MAIS, uma vez que os dados não foram consistentes em todas as variáveis.

Estudo envolvendo estudantes de Ensino Fundamental e Médio foi desenvolvido por Bragotto (1994), que buscou investigar se a criatividade poderia ser utilizada como forma de estimular o interesse dos alunos pela Língua Portuguesa, na sua forma escrita e falada. Para isso, 30 estudantes da $6^{\text {a }}$ série do Ensino Fundamental compuseram o grupo experimental e 15 estudantes compuseram o grupo controle. O primeiro grupo participou de um programa experimental, composto por 12 sessões nas quais eram demonstradas e encorajadas as expressões através da poesia, em suas diversas formas: narrada, escrita, cantada e dramatizada. Vários instrumentos foram utilizados como pré e pós-teste, tais como um questionário de atitudes e algumas atividades do teste Pensando Criativamente com Palavras de Torrance, além de poesias e redações livres que tiveram sua qualidade enquanto expressão verificada por juízes. Os resultados apontaram ganhos para quase todas as características criativas avaliadas pelo instrumento de criatividade verbal e uma mudança de atitude geral dos estudantes frente à importância da poesia e da língua portuguesa como forma de expressão emocional.

No Ensino Médio, três programas foram encontrados. No primeiro, Marin (1976 citado por Alencar \& Fleith, 2003) buscou investigar o efeito de um programa de criatividade artística na criatividade não verbal de 37 adolescentes, estudantes de $1^{\text {a }}$ série do Ensino Médio. Como forma de avaliação, dois testes de Torrance foram aplicados, antes e depois do programa. Os alunos que participaram do programa foram considerados grupo experimental e outros 37 alunos foram selecionados para comporem o grupo controle. Os resultados demonstraram que o grupo experimental obteve ganhos significativos nas características de fluência, flexibilidade e originalidade, demonstrando que o programa influiu positivamente na capacidade criativa não verbal dos estudantes.

Em outra pesquisa, Alencar (1992 citada por Alencar, 1998), implementou um programa de criatividade ao longo 
de 14 semanas, em encontros semanais de duas horas, junto a 87 alunos, divididos em grupo controle e experimental. O grupo experimental vivenciou, ao longo do programa, exercícios de aprofundamento interpessoal, de produção de ideias e técnicas de resolução criativa de problemas, assim como discussões sobre barreiras à criatividade. Como forma de avaliação, os testes verbais de Torrance e uma escala de avaliação do nível de criatividade pessoal foram empregados e indicaram diferenças significativas em todas as medidas de pensamento criativo, assim como na autoavaliação, a favor do grupo experimental.

Um terceiro programa, voltado a estudantes de curso técnico de Propaganda e Marketing, foi conduzido por Lins e Miyata (2008). Dez alunos participaram de uma oficina de criação publicitária com duração de cinco meses. Ao final da oficina, três professores avaliaram se houve ou não progresso no pensamento criativo desses alunos através da análise de dois anúncios que foram criados individualmente por cada aluno, um elaborado por ocasião do início da oficina e outro ao final. Os resultados demonstraram que os alunos conseguiram melhorar a capacidade de pensamento criativo, sendo que o espaço da oficina mostrou-se favorável e produtivo ao desenvolvimento dessas habilidades.

Somente dois programas brasileiros desenvolvidos junto a estudantes universitários foram encontrados, sendo outros cinco desenvolvidos nos Estados Unidos. No primeiro, Alencar e Virgolim (1990 citado por Alencar, 1998), solicitaram que os estudantes respondessem aos testes de pensamento criativo de Torrance e a uma escala de autoavaliação da criatividade, antes e após o programa de criatividade. Os resultados demonstraram que não houve diferenças significativas nas habilidades medidas pelo instrumento, embora mudanças tenham sido notadas na maneira como os estudantes se percebiam em termos de criatividade, sendo que aqueles que participaram do grupo experimental avaliaram-se como mais criativos após a participação no programa, sendo o inverso relatado pelos participantes do grupo controle.

Fleith e Alencar (1992), por sua vez, trabalharam com estudantes de cursos de formação de professores fazendo uso de um programa de desenvolvimento de habilidades criativas, de forma a verificar seus efeitos nas tarefas de elaborar atividades. A amostra foi constituída por 38 estudantes do sexo feminino do $3^{\circ}$ ano do curso de magistério. Destas, 17 constituíram o grupo experimental e 21, o grupo controle. O programa de treinamento constou de uma parte teórica e outra mais prática envolvendo exercícios e técnicas que estimulam a criatividade durante 16 sessões semanais de 140 minutos em um total de 40 horas. Como forma de avaliação, foram aplicadas duas atividades do Teste Verbal e duas atividades do Teste Figural de Torrance, antes e imediatamente após o término do programa. Os resultados indicaram que o grupo experimental obteve escores significativamente superiores aos do grupo controle em quatro das doze medidas avaliadas nos testes de criatividade, confirmando a eficácia do treinamento para a criatividade dos futuros formadores.

Internacionalmente, pode-se citar o estudo conduzido por Reese, Parnes, Treffinger e Kaltsounis (1976) junto a dois grupos de estudantes universitários, 145 pertencentes ao grupo experimental e 153, ao grupo controle. O primeiro grupo participou de disciplinas de resolução criativa de problemas, oferecidas durante 15 semanas ao longo do semestre, como disciplina regular do curso, de forma que parte da amostra foi acompanhada em estudo longitudinal por dois anos. No início e ao final de cada semestre, os estudantes foram testados com diversos testes baseados no modelo de estrutura do intelecto de Guilford, em um total de 38 testes já existentes e 9 que foram construídos para o estudo, divididos em cinco baterias. Os resultados do pré-teste mostraram que os grupos não diferiam significativamente, de forma que os resultados do pós-teste puderam ser comparados com a finalidade de estimar os efeitos do programa. De acordo com os resultados esperados, o treinamento surtiu efeito significativo na produção divergente, mas também na produção convergente e cognição dos alunos do grupo experimental.

Estudo de Ridley e Birney (1967) com o objetivo de avaliar o efeito do treinamento de originalidade foi conduzido junto a 159 calouros universitários do sexo masculino, avaliados a partir do uso de dois testes de Guilford (Unusual Uses e Plot Titles Test), divididos em dois grupos. O grupo experimental recebeu treinamento e instruções sobre como elaborar respostas originais em associação de palavras e no uso de técnicas de soluções de problemas. A hipótese previa que essas variáveis poderiam influenciar significativamente na performance no teste de usos incomuns e nos teste de títulos, a qual foi confirmada, dado o fato de que o grupo experimental apresentou melhores estratégias e melhor resultado nos testes do que o grupo controle.

Outro estudo, de Meadow e Parnes (1959), foi desenhado com o objetivo de avaliar os efeitos de um treinamento em resolução criativa de problemas nas habilidades criativas. O curso, com 30 horas de duração, foi conduzido junto a 54 estudantes do curso de graduação em administração de negócios, com idades entre 17 e 51 anos, os quais fizeram parte do grupo experimental, havendo um número igual de estudantes no grupo controle. Uma bateria de 10 testes foi administrada antes e depois do programa de treinamento, cujos resultados apontaram diferenças significativas entre os grupos, sendo que o experimental apresentou aumento em duas medidas de quantidade de ideias, assim como em três medidas de qualidade.

Com a hipótese de que o pensamento criativo consiste na criação de associações livres, novas e apropriadas para a tarefa, Freedman (1965) desenvolveu treinamento de associação livre com 90 estudantes ingressantes de um curso de Psicologia, sendo 80 classificados no grupo experimental (40 em um grupo que recebeu treinamento com facilitação, que consistia em um tempo livre para fazer associações livres a cada bloco de 10 palavras e outros 40 participantes que receberam treinamento sem facilitação, os quais foram estimulados a fazer associações para cada uma das palavras lidas pelo experimentador), havendo ainda 10 participantes no grupo controle. Todos os grupos foram avaliados pelo Remote Associates Test. Os resultados demonstraram que o grupo com facilitação obteve escores 
significativamente maiores que o grupo de não facilitação e o grupo controle, de forma a demonstrar que diferentes métodos de treinamento geram diferentes resultados.

Stratton e Brown (1972) testaram quatro grupos de 45 participantes cada. Um dos grupos recebeu primeiramente treinamento em julgamento e, em seguida, em produção. O segundo grupo também recebeu treinamento, mas na ordem inversa. Os dois outros grupos não receberam treinamento e constituíram os grupos controles. Os resultados aos testes de produção de títulos, julgamento e problemas não relacionados indicaram que os participantes que receberam primeiramente o treinamento em julgamento apresentaram ideias de melhor qualidade do que aqueles que receberam treinamento inicial em produção, ou que os grupos sem treinamento. Em relação ao número de soluções, os dois grupos com treinamento não se diferenciaram, embora o tenham feito em relação aos grupos sem treinamento. Assim, comparações nas medidas de produtividade (número de soluções, tempo e taxa de produção) revelaram os benefícios do treinamento.

Outros programas de treinamento criativo foram encontrados, tendo como foco professores. Como exemplo, pode-se citar a pesquisa de Fadel (2009), a qual envolveu 30 professores, divididos igualmente em dois grupos, experimental e controle. O primeiro grupo participou do programa que constava de 11 sessões semanais com duração de 3 horas cada durante o período de um semestre letivo. Nas sessões, eram trabalhadas questões teóricas e práticas relacionadas à criatividade. O segundo grupo também participou de encontros com a mesma duração, entretanto com foco no cotidiano pedagógico, tratado de forma expositiva e por meio de discussões. Como medida, utilizou-se o teste verbal de Torrance, antes e após o programa, além de atribuição de notas aos professores, dadas pelos estudantes. Diferenças significativas no grupo experimental foram verificadas em relação às características de originalidade e perspectiva incomum. De acordo Fadel e Wechsler (2011), o programa tornou possível a desmistificação de ideias errôneas dos professores sobre criatividade, assim como um aumento na nota aribuída, pelos alunos, aos professores do grupo experimental, sugerindo a influência do programa no seu trabalho.

Ainda focando o professor, Alencar, Fleith e Rodrigues (1990) desenvolveram programa de treinamento aplicado em 22 professoras de $3^{a}$ e $4^{a}$ série do Ensino Fundamental cujo objetivo era desenvolver as habilidades criativas e familiarizar os participantes com as diversas técnicas existentes para o desenvolvimento do pensamento criativo. O programa teve duração de 30 horas, sendo desenvolvido ao longo de quinze encontros semanais de duas horas. Outros 24 professores constituíram o grupo controle. Como forma de avaliação, foram utilizadas atividades verbais e figurativas do Teste de Torrance, aplicadas antes do início do treinamento e cinco meses após o seu término, além de entrevistas que envolveram questões relativas ao programa de treinamento em criatividade e percepções de mudanças em aspectos do seu comportamento, decorrentes do trei- namento. Os resultados demonstraram que os professores que participaram do treino obtiveram médias mais altas em seis medidas (fluência, flexibilidade e originalidade, verbal e figural) quando comparados aos participantes do grupo controle. As entrevistas, por sua vez, revelaram uma avaliação bastante positiva do programa por parte da quase totalidade dos professores que participaram do treinamento, indicando que o mesmo contribuiu tanto para o desenvolvimento de suas próprias habilidades criativas como de seus alunos.

Também tendo como foco o professor, Aguilar (1999) desenvolveu uma investigação com o objetivo de determinar os efeitos do treinamento da criatividade na produção de material didático de leitura e escrita em um grupo de professoras da educação primária. Tanto o grupo experimental quando o grupo controle foi avaliado antes e depois do programa de treinamento, sendo que os resultados demonstraram que o primeiro grupo obteve ganhos significativos em relação ao grupo controle, de forma que a autora sugere a utilização desse tipo de programa como forma de auxiliar a habilidade de elaboração de material didático para outros temas da aprendizagem.

Por fim, dois estudos bastante importantes devido à população minoritária envolvida, crianças com dificuldade de aprendizagem, foram encontrados. O primeiro, desenvolvido por Dias, Enumo e Azevedo (2004), buscou investigar os efeitos de um programa de promoção da criatividade sobre o desempenho acadêmico e cognitivo de 17 alunos de $2^{a}$ e $3^{a}$ séries do Ensino Fundamental com dificuldade de aprendizagem (confirmada por meio de desempenho inferior e médio inferior no Teste de Desempenho Escolar), comparando-os a um grupo-controle composto também por 17 alunos. O programa continha exercícios para as habilidades de fluência, flexibilidade e originalidade e teve a duração de 25 sessões de 60 minutos, executadas 3 vezes por semana durante 3 meses. Os grupos foram comparados pré e pós-teste por meio dos resultados no TDE, Wisc e Raven. Os resultados indicaram uma melhora significativa no desempenho acadêmico (Teste de Desempenho Escolar - TDE) e cognitivo (Raven) do grupo que participou do treinamento, de forma a indicar, segundo as autoras, que o estímulo à criatividade pode contribuir no desempenho acadêmico e cognitivo de alunos com queixa de dificuldade de aprendizagem ou atraso escolar.

O segundo estudo foi conduzido por Pereira (1996) em um grupo de 29 crianças, divididas em grupo experimental e controle, também diagnosticadas com dificuldades de aprendizagem. Como medida, foi utilizada a bateria de Torrance e um questionário de avaliação do desempenho escolar, respondido pelos professores, nas modalidades pré e pós-teste. Os resultados demonstraram ganhos por parte do grupo experimental tanto em relação ao desempenho escolar quanto nas medidas de originalidade e fluência verbal, assim como originalidade figurativa, indicando um efeito positivo do treinamento no processo de reabilitação dessas crianças.

Após conhecimento dos programas, o que se pode perceber é que pesquisas clássicas realizadas para avaliar 
a eficácia desses programas têm apontado, em sua maioria, resultados positivos em quantidade e qualidade das ideias criativas, ao comparar grupos que foram submetidos a treinamento com grupos controle, sendo mais comum a avaliação da criatividade dos sujeitos no início e após o final dos programas por meio de testes tradicionais. A revisão da literatura demonstrou que, na totalidade dos estudos, os grupos experimentais que participaram de programas de treinamento criativo apresentaram melhoras nas características criativas, além de maior motivação em sala de aula e melhora do rendimento acadêmico, de maneira que, de uma forma geral, as habilidades aprendidas nesses programas acabaram sendo ampliadas e generalizadas para diferentes propósitos e contextos.

Diante dos resultados relatados na literatura acerca dos programas de treinamento em criatividade, Wechsler (1985) aponta que uma conclusão preciosa que decorre da investigação de programas de treinamento criativos é a percepção de mudança de atitude por parte dos estudantes. A autora ainda afirma que inúmeros programas visando ao desenvolvimento da criatividade, realizados em diversas partes do mundo, mostraram ter sucesso no desenvolvimento do talento criativo através de técnicas e exercícios, em pessoas bem dotadas criativamente ou não. Opinião similar é compartilhada por Alencar e cols. (1990) ao afirmarem que a análise da literatura indica um grau relativamente alto de sucesso dos programas, confirmando a ideia de que o pensamento criativo pode ser desenvolvido através do domínio de certas técnicas e do treino.

Neste sentido, Torrance e Myers (1976) afirmam que "em nosso próprio trabalho sempre constatamos que os métodos orientados a ativar o pensamento criativo podem ser ensinados desde os cursos pré-escolares até os cursos universitários. Quase sempre os alunos melhoraram de forma notória e, algumas vezes, espetacular, sua habilidade para dar soluções originais e úteis aos problemas" (p.98). Esses resultados nos levam à constatação da importância das estratégias criativas serem incentivadas em nossas escolas, independente do nível educacional, iniciando-se desde a pré-escola, a fim de que seja proporcionado um crescimento significativo na criatividade desde os anos escolares iniciais.

Entretanto, torna-se importante destacar duas dificuldades, referentes à avaliação dos programas, apontadas por Oliveira (2007): em primeiro lugar, a complexidade da integração destes dados de forma compreensiva e precisa, visto que, por um lado, a especificidade inerente a cada tipo de programa torna difícil, ou até inviável, a possibilidade de generalização dos seus resultados, até porque a maioria destes programas inclui outras formas de intervenção além do enriquecimento. Por outro lado, verifica-se a escassez de estudos longitudinais neste domínio, à qual se alia, por vezes, a dificuldade em reunir instrumentos de avaliação com as propriedades psicométricas apropriadas. Em se- gundo lugar, diante da diversidade de amostras, métodos e resultados, devemos atentar para o fato de que cada caso merece ser avaliado e acompanhado na sua singularidade, sendo disparatado assumir receitas generalizadas (Bernardo, 2008; Pereira \& Guimarães, 2007).

Dessa maneira, o que se pode notar é que a avaliação da eficácia de um programa de criatividade é inevitavelmente polêmica, dada a dificuldade de encontrar consenso em torno da definição e medição do fenômeno que se pretende promover. No entanto, segundo Bahia (2008), num domínio de intervenção tão necessário, as iniciativas de promoção da criatividade precisam ser analisadas e avaliadas tendo em vista não só uma compreensão mais abrangente das variáveis envolvidas como também uma melhoria da própria intervenção. Ainda de acordo com a autora, independente dos problemas e dificuldades, não se pode negar o fato que os programas revelaram ser uma estratégia pedagógica capaz de oferecer ao aluno mais oportunidades de desenvolvimento do seu potencial, a manutenção de elevados níveis de motivação pela aprendizagem e a oportunidade de concretizar em desempenho os seus talentos e capacidades.

Salienta-se, no entanto, a necessidade de cautela na interpretação dos resultados apontados pelas pesquisas revisadas, dado o fato de que a presente pesquisa apresentou como limitação o fato de ter sido desenvolvida com base nos estudos acessíveis na literatura, sendo que, no caso das teses e dissertações, as informações foram retiradas, muitas vezes, somente dos resumos encontrados no banco consultado. Disso decorre o cuidado necessário, dado o fato de que os resumos, segundo Megid (1999), por serem muito sucintos e, em muitos casos, mal elaborados ou equivocados, não são suficientes para a divulgação dos resultados e das possíveis contribuições dessa produção. Por esse motivo, estudos mais amplos, envolvendo outras bases de dados, são recomendados a fim de que um quadro mais amplo e completo possa ser traçado.

Por fim, devemos reforçar a importância de se estudar a influência da concepção do professor acerca da criatividade. Se a crença de quem ensina é a de que a criatividade corresponde a um dom possuído apenas por alguns indivíduos e que sua manifestação na sala de aula é, portanto, infrequente, esta conduzirá à tendência de valorizar mais a sua promoção em contextos específicos como programas para superdotados ou, ao contrário, se os professores acreditam na criatividade enquanto potencial a ser desenvolvido em todos os indivíduos, isso enfatizará a sua responsabilidade e motivação na sua identificação e trabalho no cotidiano escolar (Morais \& Azevedo, 2008), de forma que se torna importante que esses programas sejam oferecidos não só aos alunos, mas também aos professores. Somente dessa forma a criatividade poderá ser, efetivamente, implementada e valorizada em nosso currículo escolar. 


\section{Referências}

Aguilar, S. D. C. V. (1999). Efectos de un taller integral en desarollo de la creatividad para la producción de material didáctico sobre lecto-escritura de las futuras profesoras de educación primaria del Instituto Superior Pedagógico Particular Encinas de Lima. Dissertação de Mestrado, Universidad Peruana Cayetano Heredia, Lima, Peru. Recuperado: 01 set 2010. Disponível http:// bases.bireme.br/cgi-bin/wxislind.exe/iah/online.

Alencar, E. M. L. S. (1975). Efeitos de um programa de criatividade em alunos de $4^{\text {as }}$ e $5^{\text {as }}$ séries. Arquivos Brasileiros de Psicologia, 27(4), 03-15.

Alencar, E. M. L. S. (1996). A gerência da criatividade: abrindo as janelas para a criatividade pessoal e nas organizações. São Paulo: Makron Books.

Alencar, E. M. L. S. (1998). Desenvolvendo o potencial criador: 25 anos de pesquisa. Cadernos de Psicologia, 4(1), 113-122.

Alencar, E. M. L. S. (2001). Criatividade e educação de superdotados. Petrópolis, RJ: Vozes.

Alencar, E. M. L. S., \& Fleith, D. S. (2003). Criatividade: múltiplas perspectivas. Brasília: Universidade de Brasília.

Alencar, E. M. L. S., Fleith, D. S., \& Rodrigues, A. M. (1990). Avaliação a médio prazo de um programa de treinamento de criatividade para professores do ensino de primeiro grau. Estudos de Psicologia (Campinas), 1(7), 79-97.

Antunes, A. M. P. (2008). O apoio psico-educativo a alunos com altas habilidades: um programa de enriquecimento numa escola inclusiva. Tese de Doutorado, Universidade do Minho, Braga, PT.

Bahia, S. (2008). Promoção de ethos criativo. Em M. F. Morais \& S. Bahia (Orgs.), Criatividade: conceito, necessidades e intervenção (pp.229-252). Braga, Portugal: Psiquilibrios.

Bahia, S., \& Trindade, J. P. (2010). (Re)conquistar talentos na adolescência: uma experiência nas artes visuais. Sobredotação, $11,51-62$.

Bampi, M. L. F. (1995). Efeitos de um programa para o desenvolvimento da criatividade na escrita. Dissertação de Mestrado, Pontíficia Universidade Católica de Campinas, Campinas, São Paulo.

Bernardo, C. A. A. (2008). As relações interpessoais da criança sobredotada. Recuperado: 05 jan 2011. Disponível: http:// repositorio.esepf.pt/handle/10000/68.

Bertonha, R. M. (1995). Programa para o desenvolvimento da criatividade em crianças pré-escolares. Dissertação de Mestrado, Pontíficia Universidade Católica de Campinas, Campinas, São Paulo.
Berwanger, O., Suzumura, E.A., Buehler, A.M. \& Oliveira, J.B. (2007). Como avaliar criticamente revisões sistemáticas e metanálises? Revista Brasileira de Terapia Intensiva, 19 (4), 475-480.

Biguetti, C. A. (1995). Efeitos de um programa para o desenvolvimento da criatividade verbal através do contar histórias. Dissertação de Mestrado, Pontíficia Universidade Católica de Campinas, Campinas, São Paulo.

Bragotto, D. (1994). Programa experimental para o desenvolvimento da expresssão poética em adolescentes. Dissertação de Mestrado, Pontíficia Universidade Católica de Campinas, Campinas, São Paulo.

Cartledge, C. J., \& Krauser, E. L. (1963). Training first-grade children in creative thinking under quantitative and qualitative motivation. Journal of Educational Psychology, 54(6), 295-299.

Cropley, A. J. (1999). Education. Em M. A. Runko \& S. R. Pritzker (Orgs.), Encyclopedia of Creativity (Vol.1, pp.629-642). San Diego, CA: Academic Press.

Cropley, A. J., \& Feuring, A. (1971). Training creativity in young children. Developmental Psychology, 4(1), 105.

De la Torre, S. (2008). Criatividade aplicada: recursos para uma formação criativa. São Paulo: Madras.

Dias, T. L., Enumo, S. R. F., \& Azevedo Jr., R. R. (2004). Influências de um programa de criatividade no desempenho cognitivo e acadêmico de alunos com dificuldades de aprendizagem. Psicologia em Estudo, 9(3), 429-437.

Fadel, S.J. (2009). Avaliação de um programa de criatividade para professores no ensino superior. Tese de Doutorado, Pontíficia Universidade Católica de Campinas, Campinas, São Paulo.

Fadel, S. J., \& Wechsler, S. M. (2011). Criatividade na universidade: potencialidade e possibilidade de transformação. Em S. M. Wechsler \& T. C. Nakano (Orgs.), Criatividade no ensino superior: uma perspectiva internacional (pp. 202-235). São Paulo: Vetor.

Feldman, D. H. (2000). The development of creativity. Em R. J. Sternberg (Ed.), Handbook of creativity (pp.169-189). Cambridge: Cambridge University Press.

Fernández, R. F., \& López, F. P. (1998). Estudio de tres modelos de creatividad: criterios para identificacion de la produccion creativa. Faisca: revista de altas capacidades, 6, 67-85.

Ferreira, N. S. A. (2002). As pesquisas denominadas "estado da arte". Educação \& Sociedade, 23(79), 257-272.

Fleith, D. S., \& Alencar, E. M. L. S. (1992). Efeitos de um programa de treinamento em criatividade em estudantes normalistas. Estudos de Psicologia, 2, 09-37. 
Freedman, J. L. (1965). Increasing creativity by free-association training. Journal of Experimental Psychology, 69 (1), 89-91.

Huber, J., Treffinger, D., \& Tracy, D. (1979). Self-instrutional use of programmed creativity-training materials with gifted and regular students. Journal of Educational Psychology, 71(3), 303-309.

Gagné, F. (2005). From gifted to talents: the DMGT as a developmental model. Em R. J. Sternberg \& J. E. Davidson (Eds.), Conceptions of giftedness (pp.98-120). Nem York: Cambridge University Press.

Joly, M. C. R. A. (1999). Microcomputador e criatividade em leitura e escrita no ensino fundamental. Tese de doutorado, Universidade de São Paulo, São Paulo.

Lins, J. S. C., \& Miyata, E. S. (2008). Avaliando a aprendizagem de criatividade em uma oficina pedagógica. Ensaio: Avaliação de Políticas Públicas Educacionais, 16(60), 455-468.

Lustosa, R. Z., Oliveira, K. L., \& Mello, B. N. (2010). Produção científica no contexto psicanalítico (2002-2009). Psico-USF, 15(2), 161-169.

Kaufman, S. B., \& Sternberg, R. J. (2008). Conceptions of giftedness. Em S. Pfeiffer (Ed.), Handbook of giftedness in children: psychoeducational theory, research and best practices (pp.71-91). New York: Springer.

Maimoni, E. H. (1992). Efeito do modo de contar histórias no comportamento verbal de alunos de periferia. Arquivos Brasileiros de Psicologia, 44(1-2), 104-121.

Meadow, A., \& Parnes, S. J. (1959). Evaluation of training in creative problem solving. Journal of Applied Psychology, 43(3), 189-194.

Megid, J. N. (1999). Tendências da pesquisa acadêmica sobre o ensino de ciências no nível fundamental. Tese de doutorado, Faculdade de Educação da UNICAMP, Campinas, SP. Recuperado: 10 out 2011. Disponível: http://cutter.unicamp.br/ document/?code=vtls000189131.

Miranda, L. C., \& Almeida, L. S. (2008). Estimular a criatividade: o programa de enriquecimento escolar "Odisseia". Em M. F. Morais \& S. Bahia (Orgs.), Criatividade: conceito, necessidades e intervenção (pp.279-299). Braga: Psiquilibrios.

Morais, M. F., \& Azevedo, I. (2008). Criatividade em contexto escolar: representações de professores dos Ensino Básico e Secundário. Em M. F. Morais \& S. Bahia (Orgs.), Criatividade: conceito, necessidades e intervenção (157-196). Braga, Portugal: Psiquilibrios.

Nogueira, S. I., \& Bahia, S. (2007). Gostam das minhas ideias? Percepções sobre o clima de criatividade. Em A. A. Candeias \& L. S. Almeida (Orgs.), Inteligência humana (pp.521-530). Coimbra: Quarteto.
Novaes, M. H. (1972). Psicologia da criatividade. Petrópolis, RJ: Vozes.

Oliveira, E. P. (2007). Alunos sobredotados: a aceleração escolar como resposta educativa. Tese de Doutoramento, Universidade do Minho, Braga, Portugal.

Oliveira, Z. M. F. (2010). Fatores influentes no desenvolvimento do potencial criativo. Estudos de psicologia (Campinas), 27(1), 83-92.

Pereira, M.S.N. (1996). Efeitos de um treinamento de criatividade no desempenho escolar e nas habilidades criativas de crianças com dificuldades de aprendizagem. Dissertação de Mestrado, Universidade de Brasília, Brasília.

Pereira, V. L. P., \& Guimarães, T. G. (2007). Programas educacionais para alunos com altas habilidades. Em D. S. Fleith \& E. M. L. S. Alencar (Orgs.), Desenvolvimento de talentos e altas habilidades: orientação a pais e professores (pp.163-176). Porto Alegre: Artmed.

Reese, H. W., Treffinger, D. J., Parnes, S. J. \& Kaltsounis, G. (1976). Effects of a Creative Studies Program on Structure-of-Intellect Factors. Journal of Educational Psychology, 68(4), 401-410.

Ridley, D. R., \& Birney, R. C. (1967). Effects of training procedures on creativity test scores. Journal of Educational Psychology, 58(3), 158-164.

Sánchez, M. D. P., Martínez, O. L., García, M. R. B., Renzulli, J., \& Costa, J. L. C. (2002). Evaluación de un programa de desarollo de la creatividad. Psicothema, 14(2), 410-414.

Stratton, R. P. \& Brown, R. (1972). Improving creative thinking by training in the production and/or judgment of solutions. Journal of Educational Psychology, 83(4), 390-397.

Torrance, E. P., \& Myers, R. E. (1976). La enseñanza creativa. Madrid: Santillana.

Wechsler, S. M. (1985). A identificação do talento criativo nos Estados Unidos e no Brasil. Psicologia Teoria e Pesquisa, 1(2), 140-146.

Wechsler, S. M. (1987). Efeitos do treinamento de criatividade em crianças bem-dotadas e regulares. Arquivos Brasileiros de Psicologia, 39(4), 95-110.

Witter, C. (2005). Produção científica e educação: análise de um periódico nacional. Em G. P. Witter (Org.), Metaciência e psicologia (pp. 137-154). Campinas, SP: Alínea. 


\section{Sobre a autora}

Tatiana de Cássia Nakano (tatiananakano@puc-campinas.edu.br)

Doutora em Psicologia como Ciência e Profissão , Pontifícia Universidade Católica de Campinas

Docente do programa de pós-graduação stricto sensu da Pontifícia Universidade Católica de Campinas.

\section{Endereço para contato:}

Av. Jonh Boyd Dunlop, s/n. Jardim Ipassurama. Campinas/ SP. CEP: 13060-904. 